\title{
Chemische Analyse der Heilquellen von Leuk im Kanton Wallis in der Schweiz;
}

\author{
Brunner und Pagenstecher.
}

Es finden sich zu Leuk mehre warme Quellen, die sämmtlich am Fusse der fast senkrechten Felsenwand des Gemmi entspringen, auf einer Wiese, die 4400 bis 4500 Fuss über dem Meere liegt.

Die warmen Quellen zu Leuk sind:

I. Die Lorenz - oder Hauptquelle. Diese Quelle bietet die auffallende Erscheinung dar, dass sie sich zu unbestimmten Zeiten jährlich zwei - bis dreimal trübt und einen weissen Schlamm mit sich führt. Ihre Temp. ist nach dem Mittel unserer Beobachtungen, im Juli angestellt, 40,37 $\mathrm{R}$.

Das sogenannte Goldbrünnlein scheint ein Zweig der Hauptquelle zu seyn.

II. Die drei Quellen des Armenbades. Sie liefern weniger Wasser als die Hauptquelle, fast nur $\frac{7}{8}$ soviel. Die Temp. dieser Quellen ist $37^{\circ}, 2 \mathrm{R}$.

III. Das Heilbad, eine schwache Quelle von $3_{1}, 35^{\circ} \mathrm{R}$. Temp.

IV. Die entfernter liegenden Hügelquellen, deren zwölf sind, von $38^{\circ}, 4 \mathrm{R}$. Temp.

V. Drei andere Quellen aufwärts an der Dala, von $30^{\circ}$ R. Temp.

VI. Die Roosgülle, von $29^{\circ}, 5$ R. Temp.

VII. Noch eine letzte Quelle in der Nähe der Roosgülle, von $27^{\circ}, 7$ R. Temp.

Diese letztern Quellen werden zu medicinischen Zwekken nicht benutzt. 
Die Temp. der Haupiquelle ist ziemlich constant, die der übrigen scheint sich durch Tagewässer zu modificiren. Das Gas, welches sich aus den Quellen fortdauernd in grossen Blasen entwickelt, enthält nach zwei Versuchen in 100 Volumtheilen :

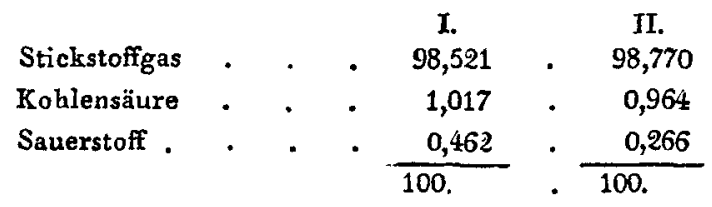

Das Gas, welches im Wasser aufgelöst ist, zeigt eine andere Zusammensetzung, wie die Schwerlöslichkeit des Stickgases und die grössere Löslichkeit der Kohlensäure zuvor vermuthen lässt. Es wurden in dieser Beziehung die Lorenzund die Armenquelle untersucht. Es enthalten hiernach 24 Unzen Medicinalgewicht des Wassers

\begin{tabular}{|c|c|c|c|}
\hline Stickstoffgas & . & $0,462 C^{\prime}$ Par. & $0,487 \mathrm{C}^{\prime}$ \\
\hline Kohlensäure & . & 0,357 & 0,312 \\
\hline Sauerstoffgas & , & 0,256 & 0,256 \\
\hline
\end{tabular}

Zur Bestimmung der festen Bestandiheile wurde ebenfalls das Wasser der beiden obengenannten Quellen untersucht. Es finden sich in 24 Unzen Wasser

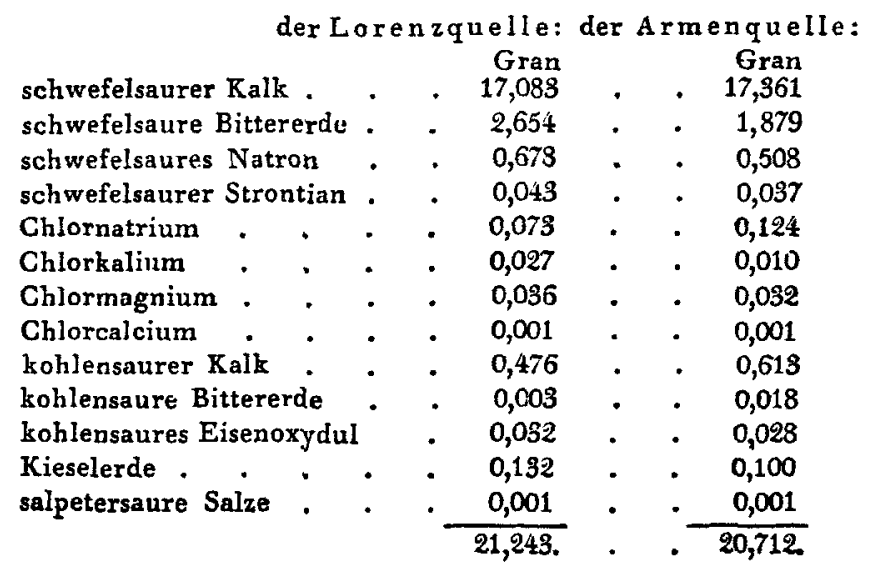


Der Absalz oder Ocker, welchen das Wasser der Lorenzquelle bildet, besteht in 60 Th. aus:

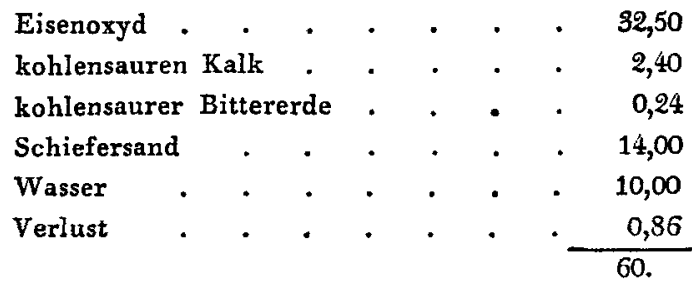

Das Gebirge, woraus die Leuker Thermen zu Tage kommen, ist Thonschiefer, der von Alpenkalk überdeckt wird. Auch diesen Thonschiefer haben Brunner und Pagenstecher untersucht. Er enthält in 6o Theilen:

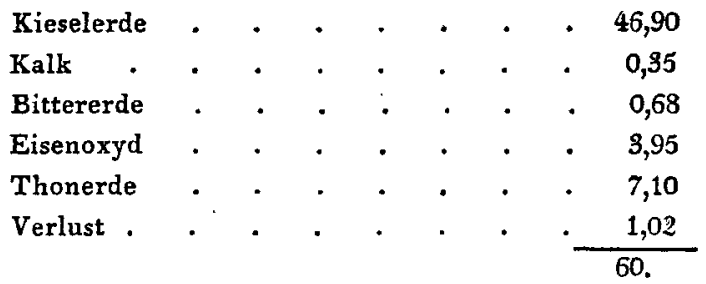

Das Wasser in den Süsswasserquellen zu Leuk ist fast rein, es enthält nur etwas kohlensauren Kalk und hat, bei 16,5 $5^{\circ} \mathrm{R}$. Temp. der Atmosphäre, eine Temperatur von $8^{\circ} \mathrm{R}$. (Aiuszug aus d. Denkschrift d. allgem. Schweiz. Gesellsch. f. d. gesainmte Naturwiss. 1829. I. 239).

Nachschrift zu vorstehendem Aufsatze.

Die Thermen von Leuk gehören zu den berühıtesten der Schweiz. Auch hier treffen wir eine Entwicklung von Stickgas an, das nach den neuesten Beobachtungen über die Thermen in den verschiedensten Gegenden als eine sehr constante Erscheinung derselben auftritt. Nach Ur e sollte das Gas, welches die Thermen zn Leuk ausgeben, fast reines Stickgas seyn. Aus den Arbeiten von Brunner und Pagenstecher ersieht man, dass dasselbe zugleich einen merklichen Theil 
Kohlensäure und Sauerstoff enthält. Was die Temperatur des Wassers der Hauptquelle betriff, so habe ich diese früher selbst untersucht. Am 15. September 1823 fand ich dieselbe $40,6^{\circ} \mathrm{R}$.

Die Meereshöhe von Leuk habe ich zu jener Zeit ebenfalls bestiunt, durch vergleichende Barometerbeobachtungen miltelst Bern und Genf. Es ergaben sich folgende Meereshöhen für Leuk, am Dalabach, miltelst Bern, $443_{1}$ Fuss und, mittelst Genf, 4493 Fuss; an der Rhone, wo man von Leuk aus dieselbe zuerst trifft, war die Meereshöhe, mittelst Bern, 2413, mittelst Genf, 2430; an der Rhone bei Sieders, mittelst Bern, 1716, mittelst Genf, 1735 Fuss.

Bekannt ist der merkwürdige Pass, der über den Gemmi nach Leuk führt.

Von der nördlichen Seite der Alpenkette, von Kandersteg, dessen Meereshöhe ich am Spiegel der Kander 3707 Fuss fand, geht man eine halbe Stunde im Thale fort, dann wird es durch Kalkfelsen enger geschlossen, über welche die Kander herunterstïrzt. Wo diese Felsen zum Gemmi ansteigen, fand ich die Meereshöhe dieses Platzes, mittelst Bern, 3907, mittelst Genf, 3926 Fuss. Der erst bewaldete Felsen wird nach und nach nackt und völlig öde. In der Hütte zu Schmaribach fand ich die Meereshöhe, 'mittelst Bern, 6488, mittelst Genf, 6447 Fuss.

Von hier führt der Weg am östlichen Ufer des Dauben Sees fort; die Meereshöhe dieses Sees zeigte sich, mittelst Bern, 6917, mittelst Genf, 6875 Fuss. Auf der Höhe des Gemmi, seitwärts vom Wege, am Fusse des Gletschers, dessen Wasser im Dauben-See fliesst, wurde die Meereshöhe, mittelst Bern, 7223, mittelst Genf, 7144 Fuss gefunden.

Die correspondirenden Beobachtungen von Genf verdanke ich dem verstorbenen Herrn Staatsrath Pictet, die von Bern Herrn Fueter. 
Nach Leuk hin fallt der Gemmi als eine steile Felsenwand herunter, fast ganz senkrecht, gegen 1600 über Leuk. In diese steile Wand wurde $1736-41$ von Tyrolern eine im Zickzack fiihrende, selbst für Maulthiere gangbare Strasse eingesprengt, gegen 10000 Fuss lang. An der einen Seite dieser Strasse hat man die senkrechte Felsenwand, an der andern fürchterliche Abgründe.

An der Südseite der Gemmi, im Thale von Leuk, sieht man sehr deutlich das Thonschiefergebürge, woraus die Quellen zu Tage gehen, das mit dem Alpenkalk überlagert ist, der die Gebirgskette bildet.

Die Bäder in Leuk sind grosse Bassins, in welchem gemeinschaftlirh in Bademäntel gebadet wird. Das Baden selbst dauert eine lange Zeit, von einer Stunde bis zu $8-9$ Stunden des Tages, und wird fortgesetzt, bis ein Hautausschlag erscheint, worauf die Badezeit wieder verringert wird. In den Bassins schwimmen kleine Tischchen, auf welchen man sein Frühstück einnehmen, oder Bücher und Zeifungen auflegen kann, um auch, neben der mündlichen Unterhaltung, hierdurch das Langweilige eines so langen Badens zu vertreiben.

B r.

\section{Ueber die Farbenänderungen des Quecksil- berjodides durch Wärme; \\ von \\ E. Mitscherlich.}

Es ist eine bekannte Erscheinung, dass mit der Temperatur bei vielen Körpern die Farbe sich ändert. Das Quecksilberjodid zeigt in dieser Beziehung ein merkwürdiges Verhalten. Sublimirt man dasselbe, so erhält man schöne gelbe krystallinische Blätter, schmilzt man es, so erhält man eine 